\title{
Efek Lidokain Intravena terhadap Nilai Numeric Rating Scale dan Kebutuhan Fentanil Pascaoperasi dengan Anestesi Umum
}

\author{
Theresia C. Sipahutar, ${ }^{1}$ Iwan Fuadi, ${ }^{2}$ Tatang Bisri ${ }^{2}$ \\ ${ }^{1}$ Rumah Sakit Siloam TB Simatupang, ${ }^{2}$ Departemen Anestesiologi dan Terapi intensif Fakultas \\ Kedokteran Universitas Padjadjaran/Rumah Sakit Dr. Hasan Sadikin Bandung
}

\begin{abstract}
Abstrak
Lidokain intravena mempunyai efek analgesia, antihiperalgesia, dan antiinflamasi. Penelitian ini bertujuan untuk mengetahui efek pemberian lidokain intravena terhadap nilai numericrating scale (NRS) dan kebutuhan fentanil pascaoperasi eksisi fibroadenoma mammae. Penelitian ini merupakan uji klinis acak terkontrol buta ganda terhadap 40 orang pasien wanita usia 18-60 tahun dengan status fisik ASA I-II yang dilakukan di Rumah Sakit Dr. Hasan Sadikin Bandung periode September 2011-Februari 2012. Sampel dikelompokkan random menjadi kelompok lidokain dan kontrol. Penilaian nyeri menggunakan numeric rating scale. Data dianalisis menggunakan uji chi-kuadrat, uji-t, dan Mann Whitney dengan tingkat kepercayaan 95\% dan dianggap bermakna bila $\mathrm{p}<0,05$. Hasil penelitian menunjukkan nilai NRS kelompok lidokain lebih rendah dan berbeda bermakna pada 30 menit $(p<0,001), 60$ menit $(p<0,001), 90$ menit $(p=0,003)$, dan 120 menit $(\mathrm{p}=0,011)$ pascaoperasi, penggunaan fentanil pertolongan pada kelompok lidokain adalah $0-25 \mu \mathrm{g}$ dan pada kelompok kontrol 25-75 $\mu$ g selama 3 jam pascaoperasi. Simpulan penelitian adalah lidokain intravena 1,5 $\mathrm{mg} / \mathrm{kgBB}$ bolus sebelum induksi dilanjutkan dosis rumatan $1 \mathrm{mg} / \mathrm{kgBB} / \mathrm{jam}$ sampai 1 jam pascaoperasi mampu menurunkan nilai numeric rating scale dan mengurangi kebutuhan fentanil pascaoperasi.
\end{abstract}

Kata kunci: Kebutuhan fentanil pascaoperasi, lidokain intravena, numeric rating scale

\section{The Effect of Intravenous Lidocaine on Numeric Rating Scale Value and Post operative Fentanyl Requirement in General Anesthesia}

\begin{abstract}
Lidocain has analgesic, anti-hyperalgesic and anti-inflamatory properties. This was a double blind randomized controlled trial study on 40 female patients, aged 18-60 years old with ASA physical status I-II who underwent excisional biopsy for fibroadenoma mammae at Dr. Hasan Sadikin General Hospital Bandung between September 2011-February 2012. The samples were randomly divided into the lidocaine and the control group. Quality of post operative pain was assessed using the numeric rating scale (NRS). The results were analyzed with chi-square test, t-test, and Mann Whitney Test with $95 \%$ confidence interval and considered significant if the $\mathrm{p}$ value $<0.05$. The results showed that in comparison to the control group, the NRS values obtained from the lidocaine group was significantly different in post operative measurement time, 30 minutes $(\mathrm{p}<0.001), 60$ minutes $(\mathrm{p}<0.001), 90$ minutes $(\mathrm{p}=0.003)$, and 120 minutes $(\mathrm{p}=0.011)$ the dose range of fentanyl as a rescue analgesic in 3 hours post operative period for the lidocaine group was 0-25 $\mu \mathrm{g}$ and 25-75 $\mu \mathrm{g}$ for the control group. This study concluded that administration of 1,5 $\mathrm{mg} / \mathrm{kgBW}$ lidocaine intravenous before induction and continued with $1 \mathrm{mg} / \mathrm{kgBW} /$ hour as maintenance dose until 1 hour post operative is able to reduce the NRS score and the requirement of post operative fentanyl.
\end{abstract}

Key words: Intravenous lidocaine, numeric rating scale, post operative fentanyl requierement

Korespondensi: Theresia C. Sipahutar, dr., SpAn. M.Kes, Siloam Hospital TB Simatupang Jl. RA. Kartini No. 8. Cilandak, Jakarta Selatan, Mobile 081320703619,Email theresia.sipatuhar@siloamhospitals.com 


\section{Pendahuluan}

Pelayanan bedah rawat jalan yang berkembang pesat beberapa dekade terakhir ini bertujuan untuk mengurangi lama dan biaya perawatan, serta meningkatkan rasa nyaman bagi pasien. Peningkatanjumlah dan kompleksitastindakan bedah rawat jalan merupakan tantangan bagi dokter anestesi untuk memberikan pelayanan yang optimal, mengupayakan pemulihan yang cepat, dan tanpa efek samping. ${ }^{1}$

Hasil penelitian observasional menyatakan bahwa kegagalan dalam penatalaksanaan nyeri pascaoperasi bedah rawat jalan menyebabkan keterlambatan pemulihan dan juga penundaan pemulangan pasien. Sampai saat ini, analgesia perioperatif berbasis golongan opioid masih menjadi pilihan utama untuk penatalaksanaan nyeri intensitas sedang dan berat. Penggunaan opiod dosis besar pada unit bedah rawat jalan berhubungan erat dengan berbagai komplikasi pascaoperasi. Kondisi ini yang menyebabkan muncul serta berkembang konsep analgesia multimodal, baik yang bersifat aditif ataupun sinergis untuk penatalaksanaan permasalahan nyeri, mengurangi kebutuhan sekaligus efek samping akibat penggunaan opioid, terutama pada prosedur bedah rawat jalan. ${ }^{1}$

Pembedahan pada fibroadenoma mammae merupakan salah satu prosedur yang sering dilakukan di unit bedah rawat jalan, dengan nyeri pascaoperasi yang cukup tinggi. Prosedur biopsi eksisional atau lumpektomi ini memiliki skala nyeri berkisar 4-8, yang bila tidak ditatalaksa secara adekuat dapat berkembang menjadi sindrom nyeri pascamastektomi atau postmastectomy pain syndrome (PMPS), yang ditandai dengan rasa nyeri seperti terbakar dan tertusuk. Nyeri tersebut dapat dicetuskan oleh penekanan ataupun gesekan. Sindrom ini lebih besar prevalensinya pada pascalumpektomi dibandingkan dengan pascamastektomi. ${ }^{2,3}$

Dalam praktik anestesi, lidokain digunakan untuk beberapa tujuan yaitu sebagai anestetik lokal, menumpulkan respons simpatis yang terjadi akibat intubasi laringoskopi, mengatasi spasme laring, dan juga terapi aritmia. Apabila digunakan secara intravena, lidokain ternyata memberikan efek analgesia, antihiperalgesia, dan juga antiinflamasi. Penelitian sebelum ini menunjukkan lidokain intravena efektif dalam pengelolaan nyeri akut. Hal dibuktikan dengan kemampuan lidokain dalam menurunkan nilai numeric rating scale (NRS) sebagai salah satu skala nyeri yang paling sering digunakan.

Penggunaan lidokain intravena perioperatif juga terbukti mengurangi penggunaan opioid perioperatif, mempercepat kembalinya fungsi pencernaan pascaoperasi, mengurangi waktu perawatan maupun rehabilitasi, serta efektif dalam mengatasi nyeri neuropatik kronik dan luka bakar. ${ }^{4-9}$

Dosis lidokain yang dinyatakan efektif dan juga aman dalam pengelolaan nyeri adalah 1-2 $\mathrm{mg} / \mathrm{kgBB} / \mathrm{jam}$. Pada dosis ini kadar lidokain plasma adalah $<3 \mu \mathrm{g} / \mathrm{mL}$ (toksisitas terjadi bila kadar plasma lebih dari $5 \mu \mathrm{g} / \mathrm{mL})^{6,7}$

Penelitian ini bertujuan untuk mengetahui efek pemberian lidokain intravena bolus 1,5 $\mathrm{mg} / \mathrm{kgBB}$ dilanjutkan dengan dosis rumatan $1 \mathrm{mg} / \mathrm{kgBB} / \mathrm{jam}$ hingga 1 jam pascaoperasi, terhadap nilai NRS serta kebutuhan fentanil pascaoperasi fibroadenoma mammae bedah rawat jalan.

\section{Subjek dan Metode}

Penelitian ini adalah penelitian eksperimental dengan metode uji klinik acak tersamar buta ganda. Kriteria inklusi subjek penelitian yaitu pasien yang menjalani prosedur pembedahan fibroadenoma mammae, status fisik American Society of Anesthesiologist (ASA) I-II berusia 18-60 tahun di unit bedah rawat jalan Rumah Sakit Dr. Hasan Sadikin (RSHS) Bandung. Kriteria eksklusi adalah wanita hamil atau menyusui, memiliki gangguan irama jantung (dikonfirmasi dengan hasil pemeriksaan EKG tidak normal di ruang operasi), alergi terhadap obat-obatan yang digunakan dalam penelitian ini, penggunaan opioid jangka panjang, serta pencandu narkoba dan atau minuman keras. Kriteria pengeluaran yaitu terjadi bradikardia (laju nadi $<50 \mathrm{x} /$ menit) selama prosedur berlangsung yang tidak memberikan respons pada pemberian sulfas atropin $0,5 \mathrm{mg}$, serta 
lama pembedahan lebih dari 1 jam.

Besar sampel dihitung berdasarkan rumus untuk menguji perbedaan pada 2 (dua) ratarata, dengan tingkat kepercayaan 95\%, besar kekuatan uji 80\%, dianggap bermakna apabila nilai $\mathrm{p}<0,05$. Jumlah sampel masing-masing kelompok adalah 22 subjek dengan drop out sebesar 10\% sehingga jumlah sampel adalah 48 subjek. Analisis statistik dilakukan dengan statistical product and service solution (SPSS) versi 13.

Setelah mendapatkan persetujuan Komite Etik Penelitian Kesehatan Fakultas Kedokteran Universitas Padjadjaran/Rumah Sakit Dr. Hasan Sadikin Bandung, dilakukan kunjungan preoperatif satu hari menjelang operasi dan juga dijelaskan tentang operasi serta penelitian yang dilaksanakan, penilaian numeric rating scale (NRS), serta dilakukan penilaian ansietas pasien menggunakan skala HARS. Randomisasi sampel dilakukan dengan menggunakan tabel bilangan random, kemudian sampel ini dibagi menjadi dua kelompok masing-masing terdiri atas 24 pasien, yaitu kelompok C (kontrol) dan kelompok L (lidokain).

Sebelum induksi, pasien dalam kelompok C diberikan $\mathrm{NaCl}$ 0,9\% $10 \mathrm{~mL}$ dan kelompok $\mathrm{L}$ diberikan lidokain $1,5 \mathrm{mg} / \mathrm{kgBB}$ ditambahkan $\mathrm{NaCl}$ 0,9\% sehingga volume menjadi $10 \mathrm{~mL}$ selama 3 menit, dilanjutkan dosis rumatan 1 $\mathrm{mg} / \mathrm{kgBB} / \mathrm{jam}$ sampai satu jam pascaoperasi. Pada saat di ruang operasi pasien dibaringkan terlentang, lalu dipasang alat-alat pemantauan serta dicatat data kesadaran, tekanan darah, laju nadi, laju napas, dan juga saturasi oksigen. Kemudian, dipasang kateter intravena ukuran 20G.

Sebelum induksi, pasien diberi cairan infus Ringer laktat $10 \mathrm{~mL} / \mathrm{kgBB}$ untuk menggantikan cairan puasa. Induksi dilakukan menggunakan propofol $2 \mathrm{mg} / \mathrm{kgBB}$, atrakurium 0,3 mg/kgBB dan fentanil $2 \mu \mathrm{g} / \mathrm{kgBB}$, dilakukan pemasangan laryngeal mask, dilanjutkan dengan pemberian ondansetron $4 \mathrm{mg}$ intravena. Pemeliharaan anestesi dilakukan menggunakan enfluran 2 vol\% dan $\mathrm{N}_{2} \mathrm{O}: \mathrm{O}_{2} 50 \%$. Bila terjadi bradikardia (laju nadi $<50 \mathrm{x} /$ detik) diberikan sulfas atropin $0,5 \mathrm{mg}$ intravena. Bila tidak terjadi perbaikan pemberian lidokain dihentikan. Segera setelah massa tumor terangkat diberikan analgetik pascaoperatif yaitu ketorolak $30 \mathrm{mg}$ intravena bolus.

Setelah operasi selesai, pasien dipindahkan ke ruang pemulihan untuk diobservasi selama 3 jam. Penilaian nyeri pascaoperasi dilakukan dengan menggunakan NRS pada 30, 60, 90, 120,150 , dan 180 menit pascaoperasi. Bila NRS lebih dari 3 diberikan analgetik pertolongan fentanil 0,5-1 $\mu \mathrm{g} / \mathrm{kgBB}$.

\section{Hasil}

Hasil analisis statistik menunjukkan bahwa variabel usia, berat badan, tinggi badan, body mass index (BMI), tingkat pendidikan, dan juga lama operasi pada kedua kelompok perlakuan tidak berbeda bermakna ( $p>0,05)$, sehingga dengan homogenitas karakteristik ini, subjek yang diteliti layak untuk dibandingkan (Tabel 1).

Hasil pengukuran terhadap tingkat ansietas preoperatif kelompok lidokain serta kontrol secara statistik tidak menunjukkan perbedaan yang bermakna $(p>0,05)$. Hasil pengukuran ini menunjukkan bahwa tingkat ansietas kedua kelompok homogen sehingga kedua kelompok layak untuk dibandingkan (Tabel 2).

Rentang nilai NRS pada kelompok lidokain dalam 3 jam pascaoperasi adalah 0-4 (Tabel 3, Gambar 1). Rentang nilai NRS pada kelompok kontrol dalam 3 jam pascaoperasi 0-6 (Tabel 4, Gambar 2). Perbandingan nilai NRS pada kelompok lidokain dengan kontrol berbeda bermakna $(p<0,05)$ pada sebagian besar hasil pengukuran, yaitu pada 30 menit $(\mathrm{p}<0,001)$, 60 menit $(\mathrm{p}<0,001), 90$ menit $(\mathrm{p}=0,003)$, dan 120 menit $(\mathrm{p}=0,011)$ pascaoperasi. Rentang nilai NRS pada kelompok lidokain adalah $0-4$, sedangkan pada kelompok kontrol 0-6 (Tabel 3).

Analgetik penyelamatan pascaoperasi pada penelitian ini digunakan fentanil $25 \mu \mathrm{g}$. Secara statistik didapatkan perbedaan yang bermakna jumlah fentanil yang ditambahkan $(\mathrm{p}<0,001)$. Pada kelompok lidokain, rentang penggunaan fentanil selama 3 jam pascaoperasi 0-25 $\mu \mathrm{g}$ dan kelompok kontrol 25-75 $\mu$ g (Tabel 4). 
Tabel 1 Karakteristik Umum Subjek Penelitian Kedua Kelompok Perlakuan

\begin{tabular}{lccc}
\hline \multicolumn{1}{c}{ Karakteristik } & $\begin{array}{c}\text { Lidokain (L) } \\
\text { (n=24) }\end{array}$ & $\begin{array}{c}\text { Kontrol (C) } \\
(\mathbf{n = 2 4 )}\end{array}$ & $\begin{array}{c}\text { Kemaknaan } \\
\text { nilai p }\end{array}$ \\
\hline Usia (tahun) & & & 0,874 \\
Rata-rata (SD) & $27,6(6,0)$ & $27,3(6,7)$ & \\
Rentang & $19-30$ & $18-35$ & 0,681 \\
Berat badan (kg) & & & \\
Rata-rata (SD) & $50,2(3,5)$ & $49,7(4,8)$ & 0,377 \\
Rentang & $45-58$ & $43-60$ & \\
Tinggi badan (cm) & & & 0,888 \\
Rata-rata (SD) & $159,4(6,1)$ & $158(5,2)$ & \\
Rentang & $146-169$ & $150-165$ & 0,944 \\
BMI (kg/m $\left.{ }^{2}\right)$ & & & \\
Rata-rata (SD) & $19,8(2,2)$ & $19,9(1,9)$ & \\
Rentang & $16,3-26$ & $16,3-23,7$ & \\
Pendidikan & & & 0,470 \\
SMP & 7 & 8 & \\
SMA & 11 & 10 & \\
Perguruan tinggi & & 6 & \\
Lama operasi & 6 & $27,1(4,6)$ & \\
Rata-rata (SD) & $28,5(5,7)$ & $20-40$ & \\
Rentang & $20-40$ & & \\
\hline
\end{tabular}

Keterangan: Nilai p pada usia, berat badan, tinggi badan, dan BMI dihitung berdasarkan uji-t. Nilai p pada variabel pendidikan dihitung berdasarkan uji chi-kuadrat. Nilai p pada variabel lama operasi dihitung berdasarkan Uji Mann-Whitney. Nilai p bermakna bila $\mathrm{p}<0,05$

\section{Pembahasan}

Prosedur bedah rawat jalan akan memberikan kontribusi penting dalam upaya mengurangi daftar tunggu pasien, serta mengurangi biaya kesehatan terutama di negara berkembang. Padabedahrawatjalan,nyeripascaoperasiyang tidak ditangani dengan baik merupakan salah satu faktor yang menyebabkan pemulihan dan juga pemulangan pasien tertunda. Sampai saat ini, analgesia perioperatif yang berbasiskan golongan opioid masih menjadi pilihan utama untuk mengatasi nyeri intensitas sedang dan berat. Namun, penelitian telah membuktikan bahwa penggunaan opiod dengan dosis besar berhubungan erat dengan berbagai komplikasi pascaoperasi. Pendekatan penanganan nyeri perioperatif secara multimodal lebih efektif bila dibandingkan dengan penggunaan opioid secara tunggal. ${ }^{1,5,13,14}$

Tabel 2 Perbandingan Tingkat Ansietas Kedua Kelompok Perlakuan

\begin{tabular}{lccc} 
Ansietas & $\begin{array}{c}\text { Lidokain (L) } \\
(\mathbf{n}=\mathbf{2 4})\end{array}$ & $\begin{array}{c}\text { Kontrol (C) } \\
(\mathbf{n}=\mathbf{2 4})\end{array}$ & $\begin{array}{c}\text { Kemaknaan } \\
\text { nilai }^{*}\end{array}$ \\
\hline Ringan & 7 & 12 & 0,140 \\
Sedang & 17 & 12 & 0,120 \\
\hline
\end{tabular}

Keterangan: *nilai p didapatkan dengan menggunakan uji chi-kuadrat 
Tabel 3 Perbandingan NRS pada Kedua Kelompok Penelitian

\begin{tabular}{cccc}
\hline Skor NRS & $\begin{array}{c}\text { Lidokain (L) } \\
(\mathbf{n = 2 4 )}\end{array}$ & $\begin{array}{c}\text { Kontrol (C) } \\
(\mathbf{n = 2 4 )}\end{array}$ & $\begin{array}{c}\text { Kemaknaan } \\
\text { Nilai } \mathbf{p}^{*}\end{array}$ \\
\hline Awal & $0(0-3)$ & $3(0-3)$ & 0,146 \\
0 & 16 & 11 & \\
$1-3$ & 8 & 13 & \\
30 menit & $0(0-3)$ & $3,5(0-6)$ & \\
0 & 16 & 4 & \\
$1-3$ & 8 & 8 & \\
$4-6$ & 0 & 12 & $<0,001$ \\
60 menit & $2,50-3)$ & $4(3-5)$ & \\
0 & 10 & 0 & \\
$1-3$ & 14 & 6 & \\
$4-6$ & 0 & 18 & \\
90 menit & $3(0-4)$ & $4(3-4)$ & \\
0 & 5 & 0 & \\
$1-3$ & 15 & 10 & \\
$4-6$ & 4 & $3(2-4)$ & \\
120 menit & $2(0-3)$ & 0 & \\
0 & 5 & 20 & \\
$1-3$ & 19 & 4 & \\
$4-6$ & 0 & $3(0-3)$ & \\
150 menit & $2(0-3)$ & 3 & \\
0 & 7 & 21 & \\
$1-3$ & 17 & $7(0-3)$ & \\
180 menit & $0,5(0-3)$ & 7 & \\
0 & 12 & 17 & \\
$1-3$ & 12 & & \\
\hline
\end{tabular}

Keterangan: ${ }^{*}$ ): Nilai median dan rentang; ${ }^{* *}$ ) dihitung berdasarkan uji chi-kuadrat. $0=$ tidak ada nyeri, $1-3$ : nyeri ringan, 4-6: nyeri sedang

Lidokain sebagai salah satu obat anestesi lokal, telah digunakan secaraintravena terbukti memberikan efek analgesia, antihiperalgesia, serta mampu mempercepat kembalinya fungsi saluran cerna. Hal inilah yang menyebabkan penggunannya dapat memberikan kontribusi dalam percepatan proses rehabilitasi pasien pascaoperasi. ${ }^{6,7}$

Infus lidokain yang diberikan secara kontinu selama operasi hingga satu jam pascaoperasi mampu mengurangi nilai VAS, mengurangi kebutuhan opioid, dan efek analgesi ini masih berlanjut hingga tiga hari pascaoperasi., ${ }^{9,14,15}$

Data karakteristik umum subjek penelitian ternyata tidak menunjukkan perbedaan yang bermakna dalam hal usia, tinggi badan, berat badan, BMI, pendidikan, dan lama operasi. Hal ini menunjukkan bahwa sampel yang diambil

Tabel 4 Kebutuhan Fentanil Pascaoperasi Kedua Kelompok Penelitian

\begin{tabular}{|c|c|c|c|}
\hline $\begin{array}{c}\text { Kebutuhan Fentanil dalam } 3 \\
\text { Jam }(\mu \mathrm{g})\end{array}$ & Lidokain (L) $(n=24)$ & Kontrol (C) $(n=24)$ & Nilai $\mathbf{p}$ \\
\hline 0 & & - & \\
\hline 25 & 20 & 5 & \\
\hline 50 & 4 & 15 & \\
\hline 75 & - & 4 & \\
\hline Median (rentang) & $0(0-25)$ & $50(25-75)$ & $\mathrm{p}<0,001^{*}$ \\
\hline
\end{tabular}

Keterangan: *) dihitung berdasarkan Uji Mann-Whitney 
untuk penelitian ini relatif homogen secara statistik ( $p>0,05)$, sehingga kedua kelompok penelitian ini layak untuk diperbandingkan.

Ansietas adalah salah satu faktor penting yang dapat memengaruhi persepsi seseorang terhadap nyeri. Pada penelitian ini dilakukan upaya untuk menghomogenisasikan persepsi subjek tentang nyeri, oleh sebab itu dilakukan penilaian tingkat ansietas menggunakan skala HARS dan didapatkan bahwa tingkat ansietas preoperatif pada kedua kelompok penelitian tidak berbeda bermakna $(p>0,05)$. Dari hasil pengukuran ini menunjukkan bahwa tingkat ansietas di antara kedua kelompok homogen sehingga layak untuk diperbandingkan.

Rentang nilai NRS kelompok lidokain dalam 3 jam pascaoperasi yaitu $0-4$, sedangkan pada kelompok kontrol berada dalam rentang 0-6. Perhitungan statistik menunjukkan perbedaan yang bermakna $(\mathrm{p}<0,05)$ pada sebagian besar pengukuran, yaitu pada 30 menit $(\mathrm{p}<0,001)$, 60 menit $(p=0,001), 90$ menit $(p=0,003)$, serta 120 menit $(p=0,011)$ pascaoperasi. Kondisi ini disebabkan karena anestesi lokal lidokain memiliki efek analgesia, antihiperalgesia, dan antiinflamasi melalui blokade transmisi saraf dari jaringan yang mengalami trauma dan regulasi inflamasi neurogenik. ${ }^{6,11}$

Lidokain intravena dan metabolit aktifnya berinteraksi dengan cara memblokade gerbang natrium pada susunan saraf perifer maupun pusat, sehingga menyupresi impuls ektopik sel -sel saraf aferen yang rusak dan menginhibisi refleks polisinaptik kornu dorsalis di medula spinalis yang akan menghambat penghantaran impuls nyeri tanpa terjadi blokade konduksi normal. ${ }^{16}$

Kerusakan jaringan maupun cedera saraf perifer akibat pembedahan akan menyebabkan reaksi inflamasi lokal ataupun sistemik. Efek antiinflamasilidokain terjadiakibatpenurunan regulasi pada sitokin proinflamasi, menyekresi antagonis reseptor sitokin antiinflamasi IL-1 (IL-1ra), serta inhibisi sintesis prostaglandin. Efek preemptif analgesia serta antiinflamasi akan didapatkan maksimal melalui pemberian infus lidokain sebelum dimulai anestesi dan manipulasi pembedahan. ${ }^{16}$

Pada pengukuran 150 dan 180 menit tidak didapatkan perbedaan bermakna nilai NRS, hal ini mungkin disebabkan karena ketorolak yang dipergunakan sebagai analgetik pascaoperasi sudah memberikan efek analgetik maksimal, seperti yang dinyatakan dalam literatur bahwa ketorolak yang diberikan intravena memiliki mula kerja 30 menit dan efek puncak dalam plasma setelah 1-2 jam penyuntikan. ${ }^{17}$

Penilaian nyeri dengan memakai NRS diikuti perhitungan kebutuhan analgetik pertolongan dilakukan untuk menilai kemampuan analgetik dalam memberikan efek analgesia yang cukup selama waktu tertentu secara kontinu. Secara statistik didapat perbedaan bermakna pada jumlah penambahan fentanil yang diberikan $(\mathrm{p}<0.001)$. Pada kelompok lidokain rentang penggunaan fentanil adalah $0-25 \mu$ g selama 3 jam pascaoperasi dan pada kelompok kontrol rentang penggunaan fentanil 25-75 $\mu$ g selama 3 jam pascaoperasi.

Hal ini mungkin disebabkan oleh pemberian lidokain sistemik mampu mengaktivasi sistem opioid endogen tubuh (terdapat reseptor pada periakuaduktal otak tengah dan juga substansi grisea periventrikuler) sehingga memberikan efek yang sinergis dengan opioid serta mampu mengurangi dosis opioid yang digunakan. ${ }^{8}$

Penelitian klinis sebelum ini menunjukkan bahwa lidokain bolus intravena dosis $1,5 \mathrm{mg} /$ kgBB dilanjutkan $1 \mathrm{mg} / \mathrm{kgBB} / \mathrm{jam}$ hingga $1 \mathrm{jam}$ pascaoperasi ternyata tidak menimbulkan efek samping. Keadaan ini didukung dari penelitian sebelumnya yang menyatakan bahwa toksisitas jarang ditemukan pada penggunaan dosis 1-2 $\mathrm{mg} / \mathrm{kgBB} / \mathrm{jam}$, sebab kadar di dalam plasma yang kurang dari $3 \mathrm{ug} / \mathrm{mL}$. Pemberian lidokain intravena dosis 1,5-2 mg/kgBB secara kontinu menimbulkan variasi kadar lidokain plasma $1,3-4 \mu \mathrm{g} / \mathrm{mL}$. Efek samping yang mungkin saja terjadi dapat diprediksi serta diatasi dengan menghentikan ataupun memperlambat infus yang diberikan. ${ }^{6,7}$

\section{Simpulan}

Berdasarkan analisis hasil penelitian, dapat disimpulkan bahwa pemberian obat anestesi lokal lidokain intravena $1,5 \mathrm{mg} / \mathrm{kgBB}$ bolus 
sebelum dilakukan induksi pada pembedahan fibroadenoma mammae (FAM), lalu dilanjutkan dosis rumatan $1 \mathrm{mg} / \mathrm{kgBB} / \mathrm{jam}$ sampai dengan 1 jam pascaoperasi mampu menurunkan nilai NRS dan juga mengurangi kebutuhan fentanil pascaoperasi.

\section{Daftar Pustaka}

1. White PF, Kehlet H, Neal JM, Schricker T, Carr DB, Carli F, dkk. The role of the anesthesiologist in fast-track surgery: from multimodal analgesia to perioperative medical care. Anesth Analg. 2007;104(6):1380-96.

2. Jaffe RA, Samuels SI. Breast conserving surgery, mastectomy and reconstruction. Dalam: Nicholson RM, Leinster S, Sassoon EM, penyunting. Anesthesiologist's manual of surgical procedures. Edisi ke4. Philadelphia: Lippincott Williams \& Wilkins; 2009. hlm. 650-2.

3. Vilholm OJ, Cold S, Rasmussen L, Sindrup $\mathrm{SH}$. The postmastectomy pain syndrome: an epidemiological study on the prevalence of chronic pain after surgery for breast cancer. BJ Cancer. 2008;99:604-10.

4. Twaddle ML. Cooke KJ. Assessment of pain and common pain syndromes. Dalam: Paice JA, Preodor ME, Roenn JH, penyunting. Current diagnosis and treatment of pain. New York: Lange; 2006. hlm. 10-20.

5. Mckay A, Gottschalk A, Ploppa A, Durieux ME, Groves DS. Systemic lidocaine decreased the perioperative opioid analgesic requirements but failed to reduced discharge time after ambulatory surgery. Anesth Analg. 2009;109(6):18057.

6. Koppert W, Weigand M, Neumann F, Sittl R, Schuettler J, Schmelz M, dkk. Perioperative intravenous lidocaine has preventive effects on postoperative pain and morphine consumption after major abdominal surgery. Anesth Analg. 2004; 98:1050-5.

7. Ferrini R, Paice JA. How to initiate and monitor infusional lidocaine for severe and/or neuropathic pain. J Support Oncol. 2004;2(1):90-4.

8. Lauwick S, Kim DJ, Michelagnoli G, Mistraletti G, Feldman L. Intraoperative infusion of lidocaine reduces postoperative fentanyl requirements in patients undergoing laparoscopic cholecystectomy. Can J Anesth. 2008;55(11):754-60.

9. Kaba A, Laurent SR, Detroz BJ, Sessler DI, Durieux ME, Lamy ML, dkk. Intravenous lidocaine infusion facilitates acute rehabilitation after laparoscopic colectomy. Anesthesiology. 2007;106:11-8.

10. Stoelting RK, Hillier SC. Local anesthetic. Dalam: Nau C, Strichartz GR, penyunting. Pharmacology and physiology in anesthetic practice. Edisi ke-4. Philadelphia: Lippincott Williams \& Wilkins; 2006. hlm. 179-203.

11. Yardeni IZ, Beilin B, Mayburd E, Levinson $\mathrm{Y}$, Bessler $\mathrm{H}$. The effect of perioperative intravenous lidocaine on postoperative pain and immune function. Anesth Analg. 2009;109:1464-9.

12. Morgan JE, Mikhail MS, Murray MJ. Pain management. Dalam: Cousins MJ, Phillip 0, penyunting. Clinical anesthesiology. Edisi ke-4. New York: McGraw Hill Companies; 2006. hlm. 359-411.

13. Saadawy IM, Kaki AM, Latief AAA, Elmaksoud AMA, Tolba OM. Lidocaine vs magnesium: effect on analgesia after a laparoscopic cholecystectomy. Acta Anaesthesiol Scand. 2010;54:549-56.

14. McCleane G. Novel approaches to postoperative analgesia for day case surgery. J One-Day Surg. 2007;18(1):4-8.

15. Mc.cleane G. Intravenous lidocaine: an outdated or underutilized treatment for pain? J Palliative Med. 2007;10(3):798895.

16. Lauretti GR. Mechanisms of analgesia of intravenous lidocaine. Revista Brasileira de Anestesiologia. 2008;58(3):280-6.

17. Puntillo K, Ley SJ. Appropriately timed analgesics control pain due to chest tube removal. J Crit Care. 2004;13(4):292-302. 